\section{Zellzählung, mikroskopische}

\author{
A. M. Gressner ${ }^{1}$ und O. A. Gressner ${ }^{2}$ \\ ${ }^{1}$ Labor Dr. Wisplinghoff Berlin, Berlin, Deutschland \\ ${ }^{2}$ Labor Dr. Wisplinghoff und Kollegen Köln, Köln, \\ Deutschland
}

Synonym(e) Zellzählung, visuelle

Englischer Begriff cell count, microscopic

Definition Mikroskopische Bestimmung der Zahl von körpereigenen (z. B. > Erythrozyten, - Leukozyten, > Thrombozyten) und/oder körperfremden Zellen (z. B. Bakterien, Pilzsporen, Parasiten) pro Volumeneinheit Körperflüssigkeit (z. B. Blut, Urin, Liquor cerebrospinalis, Erguss, Exsudat) unter Verwendung von optischen Präzisionsinstrumenten ( Z Zählkammern).

Beschreibung Die mit $>$ EDTA antikoagulierte, durchmischte $\triangleright$ Vollblutprobe wird unter Verwendung einer graduierten Mischpipette für die Zählung der $>$ Erythrozyten 1:200 oder 1:100 mit $>$ Hayem-Lösung bzw. für die Zählung der - Leukozyten 1:10 oder 1:20 mit $>$ Türk-Lösung verdünnt und in eine graduierte, hochpräzise, DIN-genormte Zählkammer eingeführt. Die anschließend mit einem plangeschliffenen Deckglas verschlossene $>$ Zählkammer wird mäanderförmig nach festgesetzten Regeln ausgezählt und die Zellzahl ( $\triangleright$ Zellzahlen, quantitative) pro Volumeneinheit (G/L) berechnet. Details zu den heute nur noch in Ausnahmefällen durchgeführten Methoden und Arbeitsvorschriften, zu den zu verwendenden Zählkammern (Neubauer-Zählkammer, > Liquor-Fuchs-Rosenthal-Zählkammer, Thoma-Zeiss-Zählkammer, Bürker-Zählkammer, Schilling-Zählkammer, TürkZählkammer, Nageotte-Zählkammer, Malassez-Zählkammer, Jessen-Zählkammer, Lemaur-Zählkammer) und den Bezugsquellen sind der Literatur und den Herstellerinformationen zu entnehmen.

\section{Literatur}

Hallman L (1980) Klinische Chemie und Mikroskopie, 11. Aufl. Thieme Verlag, Stuttgart 